graphs, and a valuable feature is the inclusion of some coloured geological maps. This memoir (published at very reasonable cost) should be in the hands of all geological visitors to this classic district.

J. G. C. Anderson

\section{ORGANIC SYNTHESIS}

Principles of Organic Synthesis

By R. O. C. Norman. Pp. xiii + 722. (Methuen: London, 1968.) $105 s$.

There are probably more known "facts" in organic chemistry than in any other single branch of science. The teaching of the subject depends on presenting a pattern or scheme into which these facts can be fitted. Until fairly recently organic chemistry was taught on a systematic approach of preparation and properties, in which the pattern was provided by structure. In the past seven years or so there has been an almost universal swing away from the systematic approach to a mechanistic approach, in which chemical reactions provide the pattern in place of compound structure. The traditionalists have fought a rearguard action, maintaining that students taught a mechanistic approach fail to appreciate the synthetic value of the reactions they learn about.

Professor Norman's book refutes this argument once and for all. After the first 200 pages the book is devoted to a treatment of all the principal synthetic reactions of organic chemistry developed from a mechanistic point of view. Reaction mechanism and synthetic utility are dealt with simultaneously in a very lucid style. The treatment both from a synthetic and from a mechanistic point of view is very up to date and the vast majority of recent synthetic mothods are described alongside the traditional processes. The book ends with brief accounts of the syntheses of a few complex natural products, giving the reader an opportunity to see the unit processes he has read about applied in a major project. The first 200 pages of the book deal briefly with elementary thermodynamies, structural theory and kinetics. This physical chemistry is not dealt with in a way that would be adequate by itself, but this is not the intention. The important point is that the student must realize that in order to understand organic chemistry, he must first understand the basic principles of physical chemistry.

In my view this is a wholly admirable text which should be compulsory reading for all university students studying chemistry. The book is expensive, but is well produced with excellent type and diagrams. The modern student must have access to more than a single text in organic chemistry. The traditional textbook with the facts listed in a systematic way is still necessary as a reference book, just as a geography student requires an atlas. To a student of organic chemistry, Norman's book is likely to be far more useful both for learning and for understanding than the traditional text.

It is the custom for reviewers to list errors both factual and typographical. There are a few of both in this book, but in a volume of more than 700 pages they are very few and do not detract from the text. My only serious criticism is that mechanisms are presented a littlo too dogmatically. I would prefer to see the phrase "the observed reaction can be rationalized by the following mechanism", rather than Norman's terse "the mochanism is as follows". The majority of organic reaction mechanisms are still only rationalizations and the drawing of curly arrows ean do no more than suggest possible reaction paths (see page 381, where curly arrows could account for the formation of 3-nitropyrrole but unfortunately 2-nitropyrrole is the product; ef. Morgan and Morrey, Tetrahedron, 22, 57; 1966).

This is a great book which will, I am sure, be regarded as an important milestone in the teaching of organic chemistry. It is an absolute "must" for the roading list of all teachers of organic chemistry and I am sure it will become included in the reading list of their students.

J. M. TEDDER

\section{II-VI COMPOUNDS}

\section{Semiconducting Compounds}

Edited by D. G. Thomas. Pp. xiv +1489. (Benjamin : New York and Amsterdam, 1967.) \$19.75.

INTEREST in the II-VI semiconducting compounds has been considerable in recent years, principally because of the need for electro-optical transducers of all kinds.

The present book contains the papers presented at an International Conference on II-VI compounds held in September 1967 at Brown University, Rhode Island, United States. Also included are 84 pages giving an edited version of the discussions at the conference; this enhances the value of the book considerably.

The papers are presented in sections. In the first section (A) the state of knowledge of the optical and luminescent properties and of defects and impurities is reviewed. There are individual papers on measurements-thermoluminescent, photoluminescent and absorption spectra, together with some coverage of the relevant theory; and on crystal imperfections in II-VI compounds.

The second section (B) begins with a review of crystal growth methods and also deals with characterization of the crystals by electrical and optical measurements.

Section C is principally about theoretical models and calculations of band structures, optical properties and so on. This is followed by individual papers in section D describing experimental measurements relating to the theory covered in the previous section. This includes such techniques as electron spin resonance, de Haas-von Alphen effect and the use of acousto-electrical effects. Section E is broadly about the transport properties of various compounds, and finally Section $F$ covers such things as electroluminescence, Gunn effect and paramagnetic resonance studies.

This is a most valuable book for anyone engaged in research in II-VI compounds and is of use to solid-stato physicists generally.

J. C. Anderson

\section{MAGNETIC MATERIALS}

\section{The Magnetic Properties of Materials}

By John E. Thompson. (Newnes International Monographs on Materials Science and Technology.) Pp. vii + 173. (Hamlyn: Feltham, Middlesex, 1968. Published for Newnes Books.) $63 s$.

As stated in the preface, this book is directed towards "scientists who are entering the field of magnetic materials and wish to read a broad, yet reasonably detailed, account, of the subject".

In recent years, the subject of magnetism has received a great deal of attention, not only in studies of the more fundamental aspects of the solid state but also in its applications to the production of and improvements in commercially interesting materials. This activity has created a need for books on magnetism and, accordingly, several excellent textbooks have appeared. Any book written to cover all aspects of the subject, however, would necessarily be of enormous proportions and so details of materials and their applications are often omitted. J. E. Thompson's book, specifically devoted to materials, is therefore to be welcomed.

It is written in six chapters intended to be self-contained so that any one may be read without reference to the remainder. The necessary background and theory of mag. netism are presented in the first chapter. Chapter 2 describes the production and properties of silicon-iron sheet 